\title{
150 anos da Confederação: momento para refletir sobre redefinições identitárias canadenses em termos de inclusão e de articulação de "comunidades de memória"
}

\section{Years of Confederation: Rethinking Canadian Identity in Terms of Inclusion and Integration of the "Communities of Memories"}

Zilá Bernd ${ }^{1}$

Submetido em 5 de março e aprovado em 9 de abril de 2017.

\begin{abstract}
Resumo: As comemorações dos 150 anos da Confederação estimulam uma reflexão sobre as redefinições das identidades canadenses no momento atual. As mobilidades culturais apresentam-se como um desafio a levar nosso pensamento para além dos nacionalismos e até mesmo dos transnacionalismos (beyond translationalisms) e nos instigam a vislumbrar perspectivas transculturais capazes de nos guiar em direção a uma possível redefinição das questões identitárias sem cair nas situações perversas de exclusão. O objetivo do presente artigo é o de partir do conceito de Pierre Ouellet proposto no livro Testaments, le témoignage et le sacré, de 2012, ou seja, o de "comunidades de memória" que pode tornar-se um instrumento para a redefinição das identidades nos contextos canadense e quebequense. Ao invés de distinguir autóctones, povos fundadores e migrantes, podemos pensar as comunidades em termos de partilha de um stock memorial comum, comunidades reagrupadas com base no compartilhamento de formas semelhantes de organização dos imaginários coletivos e de seu desejo de pertença à América. Ouellet considera que, no contexto atual de constantes migrações, mais importante do que falar de identidades nacionais ou mesmo transnacionais, é falar de "communautés de mémoire", conceito que compreende, para além da memória dos povos fundadores, as culturas dos que acabam de chegar ao país, e que vão constituir - através das trocas - uma memória múltipla que o autor chama de comunidades de memória.
\end{abstract}

Palavras-chave: Comunidades de memória. Comunidades culturais. Confederação. Testemunho.

Summary: The celebrations of the 150th anniversary of the Confederation stimulate considerations about the redefinition of Canadian identities at the present moment. Cultural mobilities present us with a challenge to take our thoughts beyond nationalisms and even transnationalisms and instigate us to foresee transcultural perspectives capable of guiding us towards a possible redefinition of identitary questions without falling in perverse situations of exclusion. The aim of the present article is to depart from Pierre Ouellet's concept, from his book Testaments, le témoignage et le sacré, from 2012, of "communities of memory" (communautés de mémoires) which can become an instrument for the redefinition of identities in the Canadian and Quebequian contexts. Instead of distinguishing autoctones, founding peoples and migrants, we could think of communities 
in terms of sharing a common memorial stock, communities regrouped acording to shared, similar forms of organization of collective imaginaries and their desire to belong to America. Ouellet considers that, in the current context of constant migrations, more important than to talk about national ou even transnational identities, it is to talk about communautés de mémoires, a concept which enconpasses, besides the memories of the founding peoples, the cultures of those who have just arrived in the country - and who will constitute - through exchanges, a multiple memory that the author calls a community of memory.

Keywords: Communities of memory. Cutural Communities. Confederation. Testimony.

Voilà le sens de toute communauté: non pas l'assemblée des hommes et des femmes placés sous une même identité, sociale ou nationale, mais le faisceau de paroles qui inscrit en chacun son appartenance au commun des mortels, à la société des vivants, à la socialité infinie de ceux qui se survivent en luttant contre la finitude par le don d'eux-mêmes [...]

Pierre Ouellet, De l'air, 2014.

Em $1^{\circ}$ de Julho de 2017, o Canadá festejará os 150 anos da entrada em vigor da Confederação. Por que essa data merece ser alvo de comemorações em todo o Canadá e em todas as embaixadas ao redor do mundo?

A partir de 1867, data oficial da assinatura da Confederação, o Canadá entra em um ciclo gradual de obtenção de sua soberania em relação ao Reino Unido, sendo sua culminância o reconhecimento da independência do país, em 1931. A confederação representa o reconhecimento do federalismo como forma de estado, de onde a importância deste documento fundador. Interessa-nos, no âmbito deste artigo, observar, pelo viés da literatura e dos estudos culturais, o processo contínuo de reinvenção do que significa "viver juntos" em um país que é independente, mas membro do Commonwealth, tendo até hoje a efígie da rainha da Inglaterra em sua moeda. Além disso é um país bilíngue com uma província que se reclama o estatuto de sociedade distinta ("société distincte"). Queremos observar o processo de reinvenção contínua a que se dedicam seus habitantes e escritores em um dos países com um dos maiores índices imigratórios do planeta, e que, portanto, caracteriza-se pela valorização da diversidade e pela busca do gerenciamento harmonioso de tal pluralidade.

A tentativa quebequense de refletir sobre os "accommodements raisonnables" 
das diferentes etnias e a interrelação de imigrantes e autóctones faz parte de uma pauta que inclui políticas como o Interculturalismo ${ }^{2}$ no Quebec e o Multiculturalismo ${ }^{3}$ no âmbito da federação canadense. $\mathrm{O}$ intenso ritmo das mobilidades culturais e o processo de integração de autóctones e imigrantes constituem-se nos avatares do processo de federalização iniciado com a Confederação há 150 anos atrás. Como pensar a identidade nacional diante de tal diversidade e do ingresso constante de refugiados oriundos dos quatro cantos do planeta? Pensam os canadenses em termos de sua pertença às Américas? O ideal do multiculturalismo de preservar aspectos identitários das diferentes comunidades étnicas e pensar-se ao mesmo tempo como membros de um país diverso é plenamente atingido? Em que medida os processos transculturais produzem alterações nos imaginários coletivos e incentivam mecanismos de contínua reinvenção de identidades nacionais e continentais? Em que medida a formulação de Pierre Ouellet das pode ser interpretada como operacional na atual conjuntura canadense diante de uma situação inédita dos vizinhos estadunidenses de estabeleceram uma política racista, anti-imigração e até de expulsão sumária de imigrantes o que se constitui em manifestação contrária aos princípios básicos do multiculturalismo?

Enquanto dirigentes de países europeus como Angela Merkel, Nicholas Sarkosy e David Cameron têm declarado que o "multiculturalismo está morto", o debate no Canadá e no Quebec pelo reconhecimento da diversidade e pela inclusão de imigrantes, assume novos contornos. Alain Gagnon refere os esforços do Quebec em implantar sua própria política de "aménagement de la diversité" (gerenciamento da diversidade), diante da questão crucial de que as minorias etnoculturais podem defender princípios incompatíveis com valores cruciais em uma democracia quais sejam a igualdade entre os sexos e a tolerância em questões de religião e sexualidade. Tentemos analisar essa espinhosa questão pelo viés de ensaios literários que analisam a literatura quebequense contemporânea com o aporte das literaturas das comunidades culturais ou das escrituras migrantes.

\section{Sobre a noção de comunidade}


As noções de comunidade e senso comum povoam a produção teórica de escritores como Simon Harel e Pierre Ouellet, preocupados com as questões de migrância e habitabilidade, questões estas que têm uma grande importância no contexto inter e multicultural do Quebec e do Canadá. Da mesma forma, Patrick Imbert insiste no sentido da importância dos encontros e do compartilhamento (partage). Todos esses autores, na esteira de Édouard Glissant, pensam a nação em uma perspectiva transversal e interrelacional com as demais nações das Américas e evitam cair na armadilha do pensamento binário que implica necessariamente em exclusões.

Várias obras de Pierre Ouellet se desenvolvem em torno da noção de "Comunidades de sentido" (Communautés de sens; identité littéraire et sens commun (2002b); Politique de la parole; singularité et communauté (2002a); L'esprit migrateur; essai sur le non-sens commun (2005) e Testaments (2012). O autor insiste, em vários textos, na ideia de que uma comunidade não é feita de um conjunto de indivíduos, nem é somente uma unidade de unidades: «elle ne peut pas être une collection d'étants ou d'individus, c'est-à-dire, des sujets objectivés existant sur un territoire et dans une histoire donnés qui leur seraient propres et leur appartiendraient» (2002 a, p. 8-9) . Em outras palavras, a comunidade não pode ter por fundamento a ideia de pertença segundo relações de inclusão e de exclusão. Ela só pode ser concebida como uma forma de coexistência que se consubstancia pela enunciação que viabiliza a comunicação entre “eu” e o outro. Segundo Ouellet, é através da palavra, isto é, da experiência enunciativa, que se criam solidariedades entre os sujeitos que passam a tornar-se membros de um "universo de discurso" que é compartilhado por todos. Conforme o autor, as comunidades se constituiriam realmente através do compartilhamento de signos no âmbito do tecido social. A originalidade de sua concepção de comunidade apoia-se na ideia de que a identidade não seria dada pela origem étnica, ou pela pertença a um território ou ainda por herança histórica ou religiosa, mas pelas condições fluidas de enunciação entre os sujeitos dando origem a um universo discursivo plenamente compartilhado. Na esteira do pensamento de Jacques Rancière, Ouellet postula que novas formas de vida em 
seja, do compartilhamento de experiências estésicas diante de obras de arte e da literatura.

Esse compartilhamento do simbólico e do sensível se refletiria nas relações políticas e sociais mais profundas, produzindo mutações na maneira de "viver juntos" dos cidadãos. Assim, o diapasão da relação dos indivíduos no seio de uma comunidade não seria dado por relações de pertença de uma parte a um todo, mas

D'une relation de co-présence ou de voisinage, de coénonciation et de cohabitation au sens fort, c'est-à-dire de mise en discours d'un monde commun et de mise au monde d'une parole commune, où le $j e$ et le $t u$, qui fondent le rapport entre identité et altérité, constituent le noyau insécable d'une intersubjectivité sensible qui se partage entre soi et autre selon une politique où communauté et singularité ne sont plus opposées mais se présupposent mutuellement [..] (2002 a, p.15-16). ${ }^{5}$

Isso criaria um novo ethos enunciativo e novas formas de subjetividade e sociabilidade nas quais singularidades e comunidades plurais poderiam substituir a denominação de identidades individuais e coletivas, uma vez que presumidamente as identidades têm como base de sustentação a pertença a uma nação, a uma religião, a uma territorialidade dada. Essa tese sustentada desde 2002 por Pierre Ouellet, levou-o a falar de uma "política da palavra (politique de la parole)" que poderia desencadear novas formas de sociabilidade em um mundo cada vez mais atravessado por mobilidades geográficas e culturais, por migrâncias de toda natureza, incluindo vagas cada vez maiores de refugiados. Essa nova política da palavra proporcionaria outros lugares de encontro promovendo a reinvenção da sociabilidade na "conjugaison inédite du devenir singulier et du destin commun" (2002b, p. 17). ${ }^{6}$

Difícil se torna acreditar que uma "Política da palavra" e sua proposta de constituição de comunidades estéticas e/ou sensíveis possa se constituir e enfrentar os diferentes tipos de intransigências religiosas, de atos terroristas e múltiplas formas de desrespeito aos direitos humanos que assumem, por vezes, configurações de violência mortífera "justificadas" por tradições ancestrais ou dogmatismos religiosos.

$\mathrm{Na}$ tentativa de pensar novas perspectivas de convivência sobre e para o Canadá no momento atual, em que as configurações geopolíticas se movimentam e se transformam tão rapidamente, tentamos entender a aposta de Pierre Ouellet na Política da Palavra e 
no desvendamento de um sentido de comunidade que respeite a singularidade. Enquanto em um estado de sociedade a palavra é sempre imperativa, para garantir o respeito às instituições, a palavra literária rompe essa cadeia de ordenamentos já que a insubmissão é sua característica primeira, sendo por natureza a própria encarnação da desobediência civil (cf. Ouellet, 2002 b, p. 7). No entender de Ouellet, a proposta de uma Política da Palavra (ou comunidade enunciativa) se materializaria em termos de comunidades de afetos (affects) ou de sentimentos, o que permitiria o estabelecimento de solidariedades profundas, que dariam lugar a formas de comunidades enunciativas que se substituiriam às “irrealizáveis comunidade dos homens" (2002a, p. 9).

Assim, seria, na perspectiva de Ouellet, nos lugares de palavra que se desfazem e se refazem os compartilhamentos de nossa experiência "da falta", (no sentido de falta de origens, de certezas fundadoras).

\section{Coletividades etnoculturais}

Em recente artigo (2016), Alain Gagnon aborda a delicada questão da posição do estado quebequense diante dos desafios da diversidade etnocultural, face à tendência em determinados países europeus, como a Inglaterra, de acelerar o integracionismo que visa a promover a adoção dos usos e costumes da sociedade de acolhida. Embora, segundo Gagnon e Boucher (2016), o Conselho da Europa considere a integração como “um processo de adaptação mútua" (2016, p. 180), é clara a postura contra o que eles chamam de comunitarismo (communautarisme), processo que se caracteriza - por parte do imigrante - por uma relação dupla entre sua cultura de origem e a cultura da sociedade de acolhida.

O Quebec desde muito está empenhado no "aménagement de la diversité" (gerenciamento da diversidade) via a política do interculturalismo ${ }^{7}$ que, embora muito estudada e empregada em documentos oficiais, não chega a ser, como o multiculturalimo, no plano federal, uma política do estado quebequense. $\mathrm{Na}$ visão de Bouchard, o interculturalismo corresponde à adoção de um pluralismo integrador, modelo baseado na busca de equilíbrios que pretendem traçar uma via entre a assimilação e a segmentação e que, para tal, acentua a integração, as interações e a promoção de uma cultura comum no respeito aos direitos 
e à diversidade $(2012$, p. 51$){ }^{8}$

O temor de que a apelação "comunidades etnoculturais" pudesse levar a um isolamento ou guetoização dessas comunidades, o Ministério da Imigração e das Comunidades Culturais (Ministère de 1'immigration et des Communautés culturelles), altera seu nome para Ministério da Imigração, da Diversidade e da Inclusão (Ministère de 1'Immigration, de la Diversité et de 1'Inclusion), num claro objetivo de promover trocas interculturais. Assim, a noção de comunidades culturais ou etnoculturais vem sendo posta de escanteio, assim como a própria noção de "sociedade de acolhida" que vem sendo substituída pela de "sociedade de pertença".

A recomendação final de Gagnon e Boucher, em tempos dos desafios criados pela imigração, é a de conceder mais importância aos temas da participação e das trocas interculturais:

Cela contribuerait (1) à contrer la reproduction de certains stéréotypes et des préjugés qui annoncent de nouvelles formes de discrimination; et (2) à éviter l'isolement des collectivités et faire en sorte que la méfiance ne s'installe pas entre celles-ci (2016. P. 195). ${ }^{9}$

\section{Comunidades culturais}

Como vimos, enquanto Alain Gagnon (2016) elege a denominação de “comunidades etnoculturais"10 , Simon Harel, em texto de 2002, utilizava, já de maneira crítica, a expressão “comunidades culturais", preferindo Pierre Ouellet (2015) falar em "comunidades de memória". Relembremos o uso por Simon Harel da expressão “comunidades culturais", em artigo de 2002 que nos parece de grande importância para entendermos a atual realidade social e literária.

Estabelecendo uma diferença entre «escritura migrante» e «literatura das comunidades culturais», aponta que a primeria "suppose une modification du sujet dans le mouvement même de la création qui s'apparente à une écriture en transit" (2002, p. 58) ${ }^{11}$, enquanto a segunda «fait référence à la mise en forme de l'ethnicité qui devient alors la transcription d'une réalité sociale» $\left(2002\right.$, p. 58) ${ }^{12}$. O autor privilegiará as escrituras migrantes, embora ressalte sua maior fragilidade que seria a de fazer "um elogio generalizado da desterritorialização" (p. 58). Considera a importância do surgimento 
dessas literaturas nos anos 1970 que obrigou de certa forma o cânone da literatura quebequense, empenhado na construção "d'un grand récit national”, a encarar essa diversidade assim como a questão das margens e da periferia. A partir dos anos 1980, as questões do "identitário" se sobrepõem às da "identidade", emergindo uma "écriture du hors-lieu comme une façon de lutter contre l'enracinement; la déterritorialisation devient un motif discursif” (2002, p. 59) ${ }^{13}$.

Esse impacto da mobilidade e do desenraizamento das literaturas migrantes sobre a literatura québécoise de souche, estimula os autores nascidos e criados no Quebec a se declararem também "migrantes" espirituais, tendo Pierre Ouellet escrito um livro sobre o "esprit migrateur" (2005) no qual conclui que é próprio do artista migrar através do mundo dos signos, elegendo suas ancestralidades culturais e literárias nas mais longínquas literaturas. O que leva a uma nova postura por parte dos escritores que passam a declarar-se: "somos todos migrantes" em nosso imaginário e, consequentemente, em nossa prática literária. Nessa medida, o que Simon Harel denomina de "escrituras das comunidades culturais", criada pelos autores ditos "étnicos", que reivindicam explicitamente sua pertença às “comunidades culturais”, passam a tornar-se embaraçosas na medida em que estariam voltadas para a construção de identidades de raiz única, enquanto os autores quebequenses bem como os da literatura dita migrante trabalhavam no sentido da construção de um identitário rizomático. Assim, no dizer de Harel,

L'écrivain migrant permettrait de renouveler l'arché du projet national. Il donnerait une puissance persuasive nouvelle aux discours identitaires collectivistes (2002, p. 64).

Contrariamente ao que alguns pensam, as escrituras migrantes estariam favorecendo um pensamento cosmopolita e híbrido. É possível verificar em autores que, além de ficcionistas são teóricos e críticos literários, como Régine Robin e Naïm Kattan, o elogio da impureza, da mestiçagem e da hibridação. A literatura não pode ser objeto de uma afirmação comunitária, conclui Simon Harel, neste artigo de 2002, publicado na revista Globe, de Montréal, já que ela é antes demais nada "la mise em jeu d'une subjectivité" (p. 69). ${ }^{14}$

\section{Pierre Ouellet e o conceito de comunidades de memória}


Com Pierre Lévy aprendemos a falar em redes de inteligência ou em comunidades de saber, o que corresponde a uma proposta marcada pela ousadia, pois nos permite imaginar a projeção de "famílias" ou "comunidades" que compartilham um estoque de saber comum. Com Pierre Ouellet vamos entrar em contato com a expressão comunidades de memória, ou seja, comunidades de autores cujas obras constituem formas semelhantes de organização e ordenação do imaginário coletivo americano. $\mathrm{O}$ conceito de "comunidades de memória" (communautés de mémoire), proposto por Pierre Ouellet, em obra de 2012 intitulada Testaments. Le témoignage et le sacré, subverte as apelações de literaturas migrantes ou transnacionais. $\mathrm{O}$ autor considera que no contexto atual de constantes mobilidades culturais, mais importante do que falar de identidades nacionais ou mesmo transnacionais, é falar de «comunidades de memória», conceito que leva em conta, para além da memória dos povos fundadores, as culturas dos recémchegados a um determinado país, constituindo através de trocas (ex-changes) uma memória múltipla que o autor denomina "comunidade de memória".

Não se trata de uma memória comum (ou coletiva) porque ela
pertence a várias tradições, com diferentes histórias, desenvolvidas
em diversos lugares, mas o fato de que pessoas de diferentes origens
participem agora da sociedade quebequense, faz com que vivamos
em uma comunidade de memórias ${ }^{15} .{ }^{16}$

Falar nos dias de hoje sobre literaturas das Américas seria falar não de uma narrativa comum, d'un grand récit des Amériques, mas de diferentes comunidades de memória (Ouellet) ou de saber (Lévy) que adotam e compartilham diferentes memórias em um verdadeiro festim antropofágico. Falando de outro modo: comunidades que compartilham um estoque memorial comum. Seguindo os ensinamentos glissantianos sobre Diversidade e Relação, seria fertilizador refletirmos sobre as Américas em termos de redes interativas e não-hierárquicas sobre as quais fala Pierre Lévy em seus últimos livros, e sobre as generosas propostas de Pierre Ouellet, com seu conceito de "comunidades de memória", bem como os de Patrick Imbert, que nos fala de (com)partilhar saberes e experiências no vasto espaço das Américas. Compartilhar as Américas para ressignificar a americanidade, na perspectiva relacional: eis um belo desafio para os anos que virão e que só pode ser alcançado pela prática de conceitos que pressupõem compartilhamento 
de memórias como o de "comunidades de memória" cunhado por Pierre Ouellet. Cremos que o Canadá tem, no momento atual - no âmbito das Américas - um papel crucial de liderança na articulação de políticas de cooperação e de articulação do que podemos chamar de a arte de "viver juntos" ("vivre ensemble"/ "live together").

No Quebec, a noção de comunidades de memória desconstrói basicamente aquela de "identidade nacional" que nos levava a acreditar na existência de arquivos memoriais que guardavam a história de um passado constituído basicamente pela herança deixada pelos ancestrais franceses e também pelo poderoso estoque memorial deixado pela religião católica. O conceito de identidade nacional do Quebec constrói-se sobre os alicerces dessa herança francófona e religiosa formatando um esquema de raiz única. Já a proposta de Ouellet de "comunidades de memória" vem destronar o conceito de identidade nacional de raiz única, propondo um conceito de identidade rizomática com sua multiplicidade de raízes, mostrando a existência de uma ancestralidade étnica, linguística e religiosa plurais (presença de autóctones, irlandeses, ingleses etc.). Nessa etapa, toma-se consciência no Quebec dos processos de hibridação que estiveram na origem de sua formação como nação. De onde a tomada de consciência de que o Canadá francês só poderia se erigir a partir da aceitação da existência de uma "comunidade de memória", incluindo-se aí memórias minoritárias (imigrantes, judeus, etc).

Por isso a literatura que contribui nos seus primórdios para preservação da herança francófona e católica, começa a partir dos anos 1980 a apropriar-se de um estoque memorial multifacetado. É ainda Pierre Ouellet que comenta o fato de os autores de sua geração, que, em sua maioria, nasceram e se criaram no Quebec, começarem a se apropriar de um imaginário migrante, deixando-se impregnar pela memória do outro.

Ce qui fait que notre mémoire, maintenant, n'est pas purement identitaire, elle est beaucoup liée à cette idée qu'on est tous, d'une certaine manière, un et peu autre. On n'est jamais totalement soi, on est rempli d'hétéronymes en nous qui parlent aussi à notre place (Ouellet, 2015, p. 235). ${ }^{17}$

Pierre Ouellet cria a esplêndida expressão "escritura coral" (écriture chorale) ${ }^{18}$ que remete à intertextualidade de suas leituras, às vozes das comunidades etnoculturais 
com as quais convive no contexto montréalais, onde vive e trabalha. Na entrevista a nós concedida para a revista Letras de Hoje da PUCRS, ele confessa que se sente habitado por múltiplas vozes daqueles com quem convive no plano pessoal, familiar e coletivo. Autor prolífero, sente que sua escritura brota de uma experiência vivida e do fato de sentir-se outro (cf Rimbaud, Je est un autre), produzindo uma literatura da mobilidade originada por um sentimento profundo "lié à cette idée qu'on est profondément autre; intérieurement autant que dans nos contacts avec autrui” (2015, p. 235). ${ }^{19}$

\section{Canadá e a contínua reinvenção da arte de viver juntos}

Todos os autores citados estão empenhados em pensar em termos de convivência harmônica da diversidade étnica e cultural canadense para além do inter e o multicultural, propondo o desenvolvimento de novas políticas de cooperação. Constatando que somos todos migrantes no plano do imaginário, no âmbito do qual podemos ultrapassar fronteiras não apenas geográficas como estéticas, Pierre Ouellet pretende elidir o dualismo nós e os outros, enfatizando que a migrância não é apenas de natureza geocultural, ligada ao deslocamento de um território a outro; “elle est aussi et peut être surtout de nature ontologique et symbolique, puisqu'elle caractérise le déplacement même du Sens et de 1'Être dans 1'expérience intime de 1'altérité" $(2005, \text { p. } 12)^{20}$.

Se somos todos migrantes no plano do estético e do sensível, podendo escolher livremente nossa ancestralidade intelectual, através da partilha do pensamento de autores dos quatro cantos do planeta, a questão do "viver juntos" pode ser encarada do ponto de vista da inclusão e não da exclusão. Retirando a questão da vida coletiva dos grandes conjuntos como estados, nações ou etnias, e colocando-a no âmbito da experiência comum da enunciação ética e estética e do universo sígnico em geral, que ligam, pela palavra e pelos signos, os membros de uma comunidade, o autor está propondo a desvinculação do identitário das relações de pertença ou não pertença, de inclusão e de exclusão. Propõe, através de uma política do sensível, a reinvenção de uma nova maneira de estar no mundo com o outro pela linguagem experimentada "comme lieu du vivre-ensemble ou de l' être-avec" (Ouellet, 2005, p. 190). ${ }^{21}$

Em Juntos (Together) (2013), Richard Senneth, reflete de modo semelhante, procurando abordar a questão da arte de viver-juntos como uma habilidade que requer a 
capacidade de "entender e mostrar-se receptivo ao outro para agir em conjunto" (2013, p. 10). A palavra-chave de sua tese é a cooperação que o autor define como uma troca em que as partes se beneficiam. Cita Michel de Montaigne como exemplo da arte de promover seu autoconhecimento observando os membros de sua comunidade. Exercitando o esquema do dom e da troca, o grande pensador francês estreia uma nova maneira de viver-junto através da vida cooperativa, livre do autoritarismo e do comando de cima para baixo. Senneth refere ainda à famosa história conhecida como o "gato de Montaigne" na qual Montaigne afirma que quando estava brincando com seu gato não sabia se seu gato estava brincando com ele. Essa passagem serve de modelo para o entendimento da cooperação, peça-chave da arte de viver juntos: o fato de não sabermos o que se passa na mente dos outros, não deve impedir nossa abertura em relação ao outro. Esses ideais humanistas que embasam o pensamento de Senneth e de Ouellet, os quais aliás já encontrávamos em Édouard Glissant, que enfatiza a abertura ao outro na perspectiva da diversidade e da relação, apontam caminhos para que - através das trocas - uma memória múltipla possa ensejar a cooperação entre os membros das comunidades que, para além da memória dos povos fundadores, se abrem às culturas dos recém-chegados, constituindo através de trocas uma memória múltipla que Pierre Ouellet denomina "comunidades de memória".

As funções de transmitir, legar em testamento, receber, fundar e construir estão ligadas às comunidades de memória que realizam a transmissão da herança cultural: é no jogo do legar, do receber e do preservar que as comunidades constroem, desconstroem e reconstroem identidades migrantes, submetendo, em muitos casos, como afirma Paul Ricoeur "a herança a inventário” (2007. p.101).

Imigração, Diversidade, Inclusão, Relação: parecem ser essas as palavras-chave que redefinem a evolução dos valores canadenses que levam o país a formas inclusivas do identitário, abrangendo memórias próximas e distantes e também os esquecimentos que são elementos integrantes dos processos mnemônicos. Na reflexão de Norberto Bobbio, “somos aquilo que lembramos” (1997, 0. 30), do mesmo modo, a nação se construirá na pluralidade de fragmentos de memórias e esquecimentos do conjunto de indivíduos que integram e também daqueles que a integraram no passado, deixando seus rastros, seus exemplos, suas marcas. Constituem essa comunidade de memórias de que nos fala Pierre 
Ouellet os que já habitavam o país antes da chegada dos europeus e todos os que vieram depois e continuam chegando para configurar uma memória identitária ou comunitária sempre em processo de renovação e de reinvenção.

\section{Referências}

BOUCHARD, G.; TAYLOR, C. Rapport. Fonder l'avenir. Le temps de la conciliation. Québe : Commission de consultation sur les pratiques d'accomodement reliées aux différences culturelles, 2008

BOBBIO, Norberto. O tempo da memória. Prefácio de Celso lafer. 9. Ed. Rio de Janeiro: Elsevier, 1997.

GAGNON, Alain-G.; BOUCHER, François. L'État québécois devant les défis de la diversité ethnoculturelle. In: GAGNON, Alain-G.; ST-CHARLES, Louis (Org.). Les conditions du dialogue au Québec: laïcité, réciprocité, pluralisme. Montreal: Éditions Québec-Amérique, Collection Débats, 2016, p. 173-196.

HAREL, Simon. Etranges étrangers ou miroirs rassurant ? De la littérature des communautés culturelles à l'écriture migrante. Conférence CRILC

http://www.crilcq.org/actualites/item/conference-de-simon-harel-etranges-etrangers-oumiroirs-rassurants-de-la-litterature-des-c/

. Une littérature des communautés culturelles made in Québec? Globe, v. 5. N.

2, 2002. https://www.erudit.org/revue/globe/2002/v5/n2/1000679ar.html

IMBERT, Patrick, L'interculturalisme. Interfaces Brasil-Canadá. 2014, 4. 14, n. 1 p.

JEDWAB, Jack. Celebrate Canada's 150th - but not as the date we became an independent country. Ottawa Citizen, 30/12/2016. http://ottawacitizen.com/opinion/ columnists/jedwab-celebrate-canadas-150th-but-not-as-the-date-we-became-anindependent-country

KYMLICKA, Will. Multiculturalismo: o sucesso, o fracasso e o futuro. Trad. de Maria Tereza Amodeo. Interfaces Brasil-Canadá, vol. 14, n. 1 (2014), p. 123-174.

LÉVY, Pierre. http://ecrans.liberation.fr/ecrans/1998/01/16/pour-pierre-levy-philosophela-cyberculture-incarne-certains-ideaux-revolutionnaires-xxie-siecle-des_225223 Acesso em 10 de maio de 2015.

OUELLET, Pierre. Testaments. Le témoignage et le sacré. Montréal: Liber, 2012. . Entretien avec Pierre Ouellet (entrevista concedida a Ana Maria Lisboa de Mello, Zilá Bernd e Marie-Hélène P. Passos). Letras de Hoje, PUCRS, v.50, n. 2, abriljunho 2015, p. 229-240. http://revistaseletronicas.pucrs.br/fale/ojs/index.php/fale/article/ view/21342

OUELLET, Pierre (Dir). Politique de la parole; singularité et communauté. Montréal: Trait d'union, 2002 a. 
OUELLET, P. ; BOUTIN, F ; LAFOREST, D. (Dir.) Communautés de sens; identités littéraitres et sens commun. Montréal: UQAM, 2002 b. (Cahiers du CELAT).

MORTON, Desmond. Breve história do Canadá. São Paulo: Alfa-Omega, 1989.

RANCIÈRE, Jacques. Le partage du sensible. Esthétique et politique. Paris: La fabrique, 2000.

. La communauté esthétique. IN OUELLET, Pierre (Dir.). Politique de la parole; singularité et communauté. Montréal: Trait d'union, 2002. P. 145- 166 (Collection Le soi et l'autre).

RICOEUR, Paul. A memória, a história, o esquecimento. Campinas: editora da Unicamp, 2007. Trad. De Alain François et. Alii.

SENNETH, Richard. Juntos: os rituais, os prazeres e a politica da cooperação. Trad. de Clovis Marques. Rio de Janeiro: Record, 2013.

\section{Notes}

1 Professora do Mestrado em Memória Social e Bens Culturais do Unilasalle, Canoas, Rio Grande do Sul. Pesquisadora 1b do CNPQ. zilabster@gmail.com .

2 Sobre a questão do Interculturalismo no Quebec, ver o excelente artigo de Patrick Imbert, v. 14, n. 1 (2014) de Interfaces Brasil-Canadá.

3 Sobre o Multiculturalismo, vale conferir a tradução de Maria Tereza Amodeo, do já célebre texto de Will Kymlicka : Multiculturalismo: o sucesso, o fracasso e o futuro, até então inédito em língua portuguesa. Interfaces Brasil-Canadá, v. 14, n. 1 (2014) p. 123-174.

4 “ela não pode ser uma coleção de seres ou indivíduos, isto é, de sujeitos objetivados existindo em um território e em uma história dados, que lhes seriam próprias e lhes pertenceriam”.

5 De uma relação de copresença ou de vizinhança, de coenunciação e de cohabitação no sentido forte, isto é, da posta em discurso de um mundo comum e de criação de uma palavra comum, onde o eu e o tu, que fundam a relação entre identidade e alteridade, constituem o núcleo irredutível de intersubjetividade sensível que se partilha em si e no outro de acordo com uma política na qual comunidade e singularidade não são mais opostas mas se se pressupõem mutuamente [..]

6 Uma conjugação inédita do devir singular e do destino comum.

7 Ver a respeito o excelente livro de Gérard Bouchard: L'interculturalisme; um point de vue québécois. Montréal: Boréal, 2012.

8 L'interculturalisme, comme pluralisme intégrateur, est um modèle axé sur la recherche d'équilibres qui entend tracer une voie entre l'assimilation et la segmentation et qui, dans ce but, met l'accent sur l'intégration, les interactions et la promotion d'une culture commune dans le respect des droits et de la diversité.

9 Isso contribuiria (1) a sustar a reprodução de certos estereótipo e preconceitos que anunciam novas formas de discriminação; e (2) a evitar o isolamento das coletividades e fazer de modo que a desconfiança não se instale entre elas.

10 O capítulo «L'état québécois devant les défis de la diversité culturelle» é inspirado em reflexões feitas a convite do Ministério da imigração, da diversidade e da inclusão - MIDI.

11 Supõe uma modificação do sujeito no próprio movimento da criação que se assemelha a uma escritura em trânsito.

12 Faz referência à formalização da etnicidade que se torna então a transcrição de uma realidade social.

13 Escritura do "fora do lugar" como modo de lutar contra o enraizamento; a desterritorialização torna-se motivo discursivo.

${ }^{14}$ A encenação de uma subjetividade.

15 Entrevista realizada com Pierre Ouellet por Ana M. Lisboa de Mello, Zilá Bernd e Marie Hélène Parret

Passos, publicada na revista Letras de Hoje, PUCRS, v. 50, n.2, abril-junho, 2015, p. 229-240.

16 «Il ne s'agit pas d' une mémoire commune (ou collective) parce qu'elle appartient à plusieurs traditions, 
plusieurs histoires différentes, plusieurs lieux où elle s'est développée, «mais le fait que tous ces gens [immigrants de différentes origines], maintenant, participent de la société québécoise, ou canadienne française, fait en sorte que l'on vit dans la communauté de mémoires».

${ }^{17} \mathrm{O}$ que faz com que nossa memória, agora, não seja puramente identitária, a está ligada à ideia de que somos todos, de um certo modo, um pouco outro. Não somos totalmente nós mesmos (soi), mas preenchidos por heterônimos que falam também em nosso lugar.

${ }^{18}$ Entretien avec Pierre Ouellet, Revista Letras de Hoje, PUCRS, 2015, p. 234.

${ }^{19}$ Ligado a essa ideia de que somos profundamente outro; interiormente tanto quanto em nossos contatos com o outro.

20 "ela é também e talvez sobretudo de natureza ontológica e simbólica, pois ela caracteriza o próprio deslocamento do Sentido e do Ser na experiência íntima da alteridade".

${ }^{21}$ Experimentado como lugar do viver-junto ou do estar-com (Ouellet, 2005, p. 190). 